\title{
Between Being Readable and Being a "Translation": A Study of Dawn of Dreams
}

M. Sridhar and Alladi Uma

\begin{abstract}
How do we as translators who do not know the "original" language, Urdu perceive Dawn of Dreams? To us then the English text becomes the "original". How then do we look at the author of the Urdu text, Abdus Samad and the translator/ author of the English text, Mehr Afshan Farooqi? Are we to look only at the themes in the text and their relevance to contemporary India? Abdus Samad wrote the book in 1991. Mehr Afshan Faroogi translated it in 2001. We are given to understand that she has edited the text, even omitting chapters. We cannot but read the text aware of this fact and wondering what has been left out and why. Would her choice have been determined by notions of readability, about the balancing act of a translation being readable and reading like a translation? Would it have been determined by her location as a Muslim woman in the 21st century? We have no answers to these directly as we know no Urdu. We have to depend on others' views on these-but those are just their readings. So we have no option but to go by the English text, even as our reading may be coloured by other people's views. At a time when we are bombarded with images of Muslims being equated with terrorists, this text becomes all the more significant. The text is not just a re-visiting of Partition, but a re-locating of Partition in the present context. It is the translating of the experiences of Muslims who are trying even today to assert their "national" identity. Our paper attempts to come to terms with some of the above issues.
\end{abstract}

How do we as translators who do not know the "original" language, Urdu perceive Dawn of Dreams? To us then the English 
text becomes the "original". How then do we look at the author of the Urdu text, Abdus Samad and the translator/author of the English text, Mehr Afshan Farooqi? Are we to lookonly at the themes in the text and their relevance to contemporary India? Abdus Samad wrote the book in 1991. Mehr Afshan Farooqi translated it in 2001. We are given to understand that she has edited the text, even omitting chapters. We cannot but read the text aware of this fact and wondering what has been left out and why. Would her choice have been determined by notions of readability, about the balancing act of a translation being readable and reading like a translation? Would it have been determined by her location as a Muslim woman in the 21st century? We have no answers to these directly as we know no Urdu. We have to depend on others' views on these-but those are just their readings. So we have no option but to go by the English text, even as our reading may be coloured by other people's views. At a time when we are bombarded with images of Muslims being equated with terrorists, this text becomes all the more significant. The text is not just a re-visiting of Partition, but a re-locating of Partition in the present context. It is the translating of the experiences of Muslims who are trying even today to assert their "national" identity. Our paper attempts to come to terms with some of the above issues.

Reader: What a translation! It reads so smooth you don't feel like putting it down. It reads like an original.

Theorist: Don't tell me! How can it read smooth and like an original? There's something wrong.

Don't you know a translation must read like a translation?

Translator: I have put my heart and soul into it. I have been as close to the original as I can possibly be.

Publisher: The translation has come out great. It can reach an international audience.

Theorist: If the translator has indeed been very close to 
Between Being Readable and Being a "Translation": A Study of Dawn of Dreams

the original, the translation cannot read smooth. It is sure to be rugged. Why should it read smooth at all? Doesn't the reader know when he picks it up, that it is a translation?

Translator: When I say I have been very close to the original, I am talking about being close to the spirit of the original. Not the word. How can I not think of my own readers and my own audience?

Publisher: There you are. The translation is meant for another set of readers and is done as you know, at another time period. We need to take this into account. It reaches another linguistic group.

Theorist: $\quad$ You are talking as if the linguistic group is so homogenous that they all speak one kind of English. Don't we talk of Englishes now?

Writer: Where am I in all this? Is it my book you are talking about or somebody else's?

Translator: It is of course your book. I have utmost respect for the writer. That's why I try my best to bring the flavour of the original into my translation. There is a need to take the best works of my language to a wider audience. To ensure a wider reach and a greater readability, I may need to sometimes edit the source text.

Publisher: That's fair enough. Also, don't forget we need to keep its marketability in mind.

Writer: $\quad$ Flavour-it's icing on the cake, is it?

Translator: Isn't a translation a re-creation? In India we have always had the tradition of translation as rewriting. We have added to the source, subtracted from it, deviated from it etc., 
without ever feeling disrespect to the original author or bothering about the so-called "fidelity" principle.

Writer:

Isn't translation also supposed to be a labour of love? Is it not a result of a translator's complete surrender to the force of the original? Don't bring in all these new fangled ideas of activism in translation and so on and so forth.

Reader: $\quad$ Stop it. Enough of all your discourses on translation. All we readers need is an engaging text.

We read Dawn of Dreams - it was indeed a "dream" reading for both of us. So smooth and so gripping! But the reality of the issues and the relevance "dawns" even to those of us who have not directly been affected by it. At the end of 2009, a decade and a half after the Urdu text by Abdus Samad was published and eight years after its translation into English by Mehr Afshan Farooqi the issues are ever present. As two outsiders, outsiders to the language, religion and to the traumatic Partition and its after effects, how do we view such a work? Are we to view it only as a story of Anwar who decides to stay back in India and is hopeful of the Nehruvian "dream" of secularism? Isn't also the story of Afaq who goes through varied stages of life even to be muted by the unspoken third degree practices of the police but finds his voice through the inspiration of the activist Kulsum? It is here that the statement of Taqi Ali Mirza in his review of the English translation becomes relevant. He compares the text to Attia Hossain's Sunlight on a Broken Column: "The closest parallel that the reviewer can think of is Atia Hossain's extremely well-written, but largely forgotten novel, Sunlight on a Broken Column."

While acknowledging the comparison that the two texts draw in terms of the effects of the partition on a family, what 
distinguishes the two would be that Attia Hossian's text is surely a woman's text. It is Laila's. It is not fair to expect a man like Abdus Samad to view partition through a woman's perspective. But when he has portrayed a character like Kulsum who becomes an inspiration to Afaq and makes him the man he is at the end of the novel, we wonder how to understand the following. While appreciating the work Kulsum is doing to rehabilitate destitute women, Afaq offers her "delicate" shoulders his "support":

"You are very brave Kulsum. I respect your dedication. But this world is a practical place, your shoulders are delicate, they do need support. When you find a compatible companion, this world will seem a different place. Think about it Kulsum."

Kulsum looked at him bashfully, and lowered her eyes. (Samad 305)

How would a woman translator have responded to such a description in the original? If a woman of an earlier generation like Attia Hossain had been able to create a woman's perspective (and we must make a reasonable guess that she [Mehr Afshan Farooqi] must be aware of Attia Hossain and her work), how would a woman translator have dealt with such an ambivalent attitude in Samad's text towards women? Taqi Ali Mirza in his review mentions that "she [Mehr Afshan Farooqi] has, one likes to suggest, enhanced its total effect by slightly reducing its size by omitting several passages and occasionally, whole chapters, to give the narrative greater vigour." We wonder why the translatorial intervention did not come in the instance of the reading of the text (if we agree that translation is also a reading of the text) as far as the woman is concerned? At least a reference to the way she reads this issue in the text must have found its way into the translator's note which may have made a difference to our reading of the English text. One would expect the translator to not only indicate the portions that have been edited out from the source, but to account for them.

The translation appears in 2001, three years after Urvashi 
Butalia published The Other Side of Silence: Voices from the Partition of India. It is quite possible that Mehr Afshan Farooqi may not have been unaware of this work. Urvashi Butalia says that she undertook to re-visit Partition after the assassination of Indira Gandhi in 1984 and the riots that followed it:

It took the events of 1984 to make me understand how ever-present Partition was in our lives too, to recognize that it could not so easily be put away inside the covers of history books. I could no longer pretend that this was a history that belonged to another time, to someone else. (5)

She further goes on to add that there is a "human dimension to history" (6) (something that Abdus Samad's text addresses too) and that she has "come to this work through a political-and personal-engagement with history, contemporary communalism, and a deep and abiding belief in feminism" (Butalia 9). While the last part, i.e., "abiding belief in feminism" may not be attributed to Abdus Samad, we know that, as Mehr Afshan Farooqi puts it, "It [Dawn of Dreams] shares with us the agony of a generation whose parents chose to stay back" (ix). Recording voices, selecting them, translating them (in the case of Urvashi Butalia) and editing them-these processes in an oral narrative indicate that the compiler/translator/editor's perspective comes through in the work. So we have one more (and many more of those recorded voices) giving us a chance to understand a "time past" and a "time present" through the reading/s of the "time past". What we have in Mehr Afshan Farooqi's translation of Abdus Samad's text is such an instance. If we were to go by the translator's note that she wanted to retain the flavour of the original yet allow the text to reach out and put it alongside with Taqi Ali Mirza's statement that portions of the source text were left out, we wonder how the woman's angle comes in or why the woman's voice does not problematise the issues relating to the women including Aliya Khatun and Fakhru Chacha's wife.

All of us are aware of Alok Bhalla's enormous contribution to the study of Partition. His introduction to this translation 
attempts to place the text in its historical and literary contexts. Concentrating on Anwar, he discusses how Anwar accepted the abolition of the zamindari system and wanted to go ahead with the new Nehruvian notions of secular democracy. He views Abdus Samad's text as one that "disrupts the grand historical narratives constructed by Pakistani scholars like I. H. Qureshi, K. K. Aziz, Aziz Ahmed and Muhammad Umar Memon, who see the emergence of an Islamic state" (xvii) and "offers a sharp rebuke to the Hindu communalists" (xviii). He has also provided us a way of viewing Fakhru Chacha with reference to characters in works like Saadat Hasan Manto's Toba Tek Singh, Bhisham Sahni's Tamas and Krishna Baldev Vaid's Guzra Hua Zamana. We wish he had also read this text alongside the works of K. A. Abbas, Attia Hossain and Urvashi Butalia. Maybe we would then have been able to understand how leftist writers (Progressive Writers Association), women writers and feminist writers dealt with these issues. We have commented on the introduction because we view this as also the translator's note as part of the text.

Coming back to the main text, we find it puzzling why Parvez's relationship with the young boy (hinting at a homosexual relationship) finds place in a text which does not seem to be concerned with this issue. We wonder whether an answer was hinted at or explained in the edited pages of the original. Another perplexing issue in the book deals with the questions of "good blood". A text that challenges fundamentalism of any kind seems to legitimize "good blood" in the way it treats characters like Sabir and Jabir and the next generation, Wasim. While they can make it big in the material world, they can never be thought of as "good blood" and the only way this can be rectified is through a marriage, that too of a girl (Kulsum) with a boy (Afaq) of "good blood"!

Let us now return to the imaginary conversation between the reader, the theorist of translation, the translator and the publisher with which we began our paper. Questions of readability of a translation, the unique quality of a translation as translation 
vs. the so-called "fidelity" to the source text, the inevitability of a target-oriented translation, its marketability, and finally the right to edit the source vs. the author's copyright are complex questions that involve several players who approach the end product with their own specific location. But the problems become more complicated when the translation pertains to an issue based text such as Abdus Samad's Dawn of Dreams on the question of Partition. Such a text raises serious questions on the ethics of translation, questions that involve not only the translator's right to edit out portions of the source text, but even of the author's right to permit any editing.

Rights of course must go with their corresponding duties. All of us-writers of works to be translated into another language, translators, publishers and readers-are aware of the fact that translation is not a simple transfer of the linguistic material from one language to another, but that it entails an enormous responsibility on all the players. Mehr Afshan Farooqi herself refers to this novel by Abdus Samad as "a timely sequel" to several anthologies of already published Partition stories (ix). Naturally, we expect the translation too to locate itself in the context of Partition literature or Paritition-like contexts obtaining in the present. Similarly, when the text moves in the direction of Kulsum, the woman protagonist in the novel, a novel that specifically mentions the Prime Minister being a woman, we expect an empathy to the woman's cause both on the part of the male writer and the woman translator. We are not suggesting that as a translator, Mehr Afshan Farooqi should have "re-written" the source to satisfy our expectations. We are only wondering if a direction towards the way she would have wanted us to read the text could have been provided in a longer translator's note. But all this is not to take away from the theme/s of the novel, the relevance of the text to the present day or the fact that this novel in Urdu is made available precisely because of a very readable translation to non-Urdu speakers in India and outside. 


\section{REFERENCES}

Butalia, Urvashi. The Other Side of Silence: Voices from the Partition of India. Durham: Duke UP, 2000.

Mirza, Taqi Ali. "Betrayed Dream.”

http://www.thehindu.com/thehindu/2001/09/02/

stories/1302017p.htm, October 5, 2009.

Samad, Abdus. Dawn of Dreams. Trans. Mehr Afshan Farooqi. Chennai: Macmillan, 2001. 